\title{
Computer Attitude of Teaching Faculty: Implications for Technology-Based Performance in Higher Education
}

\author{
Josephine A. Larbi-Apau and James L. Moseley \\ Wayne State University, Detroit, MI, USA
}

\author{
jlarbiapau@wayne.edu james.moseley@wayne.edu
}

\section{Executive Summary}

This study examined the validity of Selwyn's computer attitude scale (CAS) and its implication for technology-based performance of randomly sampled $(n=167)$ multidiscipline teaching faculty in higher education in Ghana. Considered, computer attitude is a critical function of computer attitude and potential performance. Composed of four constructs, and using a five-point Likert rating scale, the CAS measured affective, perceived behavioral control, behavior, and perceived usefulness attitudes as multi-construct of computer attitude. The reliability of the overall computer attitude and all four constructs scales are positive with high internal consistencies $(>.70)$ and significant construct validity $(p<0.001)$. Analysis of variance (ANOVA) showed significant mean differences across all four constructs at $p=0.001$. Affective attitude was the highest contributor of computer attitude followed by perceived usefulness, behavior, and perceived behavioral control attitudes. The teaching faculty has relatively high positive computer attitude; with purposeful practice and enabling environment, they can manage technology-oriented proficiencies and professional performances effectively. Further studies in private and public universities worldwide are proposed for practical and academic significance. In addition, relational and invariance of CAS across demographic factors such as gender, age, academic status, and subject discipline are proposed for their differential influence.

Keywords: affective, behavior, computer attitude, control, higher education, ICT, teaching faculty, usefulness.

\section{Introduction}

The proliferation of information and communication technology (ICT) policies and practices in higher education has resulted in rapid changes to the traditional academic roles of teaching faculty and students (Bonk \& Dennen, 2003; Morris, Xu, \& Finnegan, 2005). Such changes and strategies include pedagogy, management of learning and classroom resources, social networking and community building, and technical support. As major leaders of transformation in the teach-

Material published as part of this publication, either on-line or in print, is copyrighted by the Informing Science Institute. Permission to make digital or paper copy of part or all of these works for personal or classroom use is granted without fee provided that the copies are not made or distributed for profit or commercial advantage AND that copies 1) bear this notice in full and 2) give the full citation on the first page. It is permissible to abstract these works so long as credit is given. To copy in all other cases or to republish or to post on a server or to redistribute to lists requires specific permission and payment of a fee. Contact Publisher@InformingScience.org to request redistribution permission. ing-learning process, significant pedagogical impact rests with the teaching faculty; a change in attitude can provide potential break-through towards accepting and developing technology-based competencies for the desired performance and change. Deep rooted attitude such as fear of the unknown and anxiety can impede ICT utilization in education. 
Attitude is related to performance and appears to have substantial influence on computer utilization and technology-based performance (Jegede, Dibu-Ojerinde, \& 1lori, 2007; Jegede \& Owolabi, 2005); however, some teaching faculty feel intimidated by technology and would rather not explore the potentials for pedagogy and professional advancement. Others are threatened by the lack of control in the technology-oriented classroom, especially, where students are more technology savvy (Larbi-Apau, 2011). Factors such as beliefs, resistance, and personal teaching philosophy can directly influence the adoption, integration, and instructional use of ICT, hence, the need to examine users' personal attributes and their implications for collective and differential technology-based performances and potential interventions.

It is important to understand and consider the socio-economic, financial, and cultural contexts in order to design and promote new technology in emerging economies (Park \& Moser, 2008), but studies about the teaching faculties' attitudes and willingness are required to fit their behaviors in these contexts. Albion (1999) argued self-efficacy beliefs can provide a contextual measure of preparing teachers to teach with technology, as Selwyn (1997) considered user's attitude an integral part of educational computer use and initial acceptance. Selwyn argued, "Attitudes influence not only initial acceptance, but also future behaviors regarding computer" (p. 35). Hence, the relationship between the human-computer interface and the set of skills for the desired performance outcomes is of particular importance, not only for this study, but also for theory and practice. The current study is developed within the framework of theory of planned behavior (Ajzen, 2005) and Selwyn's (1997) Computer Attitude Scale (CAS).

\section{Attitude}

Attitude is defined by Ajzen (2005) as "a disposition to respond favorably or unfavorably to an object, person, institution, or event" (p. 3). In his theory of planned behavior, Ajzen (1988; 2005) linked attitude and behavior through the description of three types of belief systems that guide human behavior; namely, behavioral beliefs, normative beliefs, and control beliefs. Indicated by favorable or unfavorable attitude toward the behavior, the behavioral belief system produces consequences. Normative beliefs describe expectations of others and can produce result based on subjective norm or perceived social pressure. Control beliefs produce perceived behavioral control and may facilitate or impede performance of the behavior. A combination of these three belief systems produces a behavioral intention, which is assumed as an immediate antecedent of behavior. Therefore, attitude can influence actual behavior directly.

\section{Selwyn's Computer Attitude Scale (CAS)}

Partly influenced by Ajzen's (1988) theory of planned behavior, Selwyn's (1997) CAS instrument has provided comparative measures for computer attitude in many contexts and audiences due to its high internal significant consistency and reliability score ( 0.87 to 0.93$)$, coefficient of stability, and construct validity $(p<0.001)$. CAS was initially tested on students between ages 16-19 years and has been applied in studies of teaching faculty in higher education (e.g., Chin, n.d.; Jegede \& Owolabi, 2005) and is found relevant for the purpose of the present study. Selwyn's CAS is composed of four distinct constructs: affective attitude (fear, discomfort, and hesitation), perceived control attitude (ease or difficulty of computer use), perceived usefulness (degree of relevance in improving job performance), and behavioral attitude (intentions and actions). The summated set of individual items in these sub-domains represents the computer attitude and reflects the degree to which respondents' attitude is favorable or unfavorable towards the attitude object. 


\section{Effects of computer attitude}

Computer attitude is cited in many studies as a correlate with technology-enriched learning environment (Hsu, Wang, \& Chiu, 2009, Jegede et al. 2007; Jegede \& Owolabi, 2005). Related studies have addressed students' attitude towards computer-technology and learning environments (e.g., Cázares, 2010), teachers in general (e.g., Yaghi \& Abu-Saba, 1998), and a few on university teaching faculty (e.g., Yushau, 2006). Studies on university teachers have ranged from the relationships between ICT competence and attitude (e.g., Jegede et al. 2007), computer attitude as correlates of computer self-efficacy (Jegede, 2007), and assessment of attitude towards computers and its implication on the use of IT in school (Chin, n.d.) among others.

With very few exceptions, the general findings on both students and teachers suggest attitude is related to performance and appears to have substantial influence on computer utilization and technology-based performance in education. For example, using a linear trend ANOVA in atheoretical study of problematic Internet use (PIU), Kim and Davis (2008) found low self-esteem and anxiety to be related to PIU, based on a set of defined positive and negative Internet activities such as social networking, music, and/or movie downloads.

Kadijevich (2002 cited in Yushau, 2006) found computer attitude coming on top of four identified critical factors as means for proper and effective use of computer technologies in the mathematics classroom. Other factors considered are software selection, proper utilization direction, and web-based professional development. Using both descriptive and inferential analysis, Jegede and Owolabi (2005) reported a somewhat positive relationship of teaching faculty's computer attitude with little variances; however, a significant relationship between computer attitude and computer access was indicated. In contrast to these findings, Cázares (2010) found no relationship between proficiency and attitude towards data analysis and information technologies and concluded proficiency level was not predicted by attitudes - negative or positive. Rather, proficiency levels were predicted by abilities such as e-searching and downloading skills. Notwithstanding, the fear of computer technology, which is accompanied by anxiety, feeling of nervousness, intimidation, and hostility, can lead to computer technology resistance (Yaghi \& Abu-Saba, 1998 ) and vice versa, hence the need for further studies in a different context where policy makers are debating the potentials of ICT in education.

\section{Assessment of computer attitude}

For many of the published attitude assessment studies, the Generalized Self-Efficacy Scale (GSES) and the Computer Attitude Scale (CAS) have been applied in predicting defined research outcomes. While the GSES model is found more related to perceived personal competency and ability to deal with a variety of stressful factors, rather than potential performance (Schwarzer \& Jerusalem, 1995), the CAS combines affective dimensions including perceived fear and anxiety, as well as control, behavior, and usage. In most cases, the Likert type attitude scales were developed and validated for the measurement of computer attitudes (e.g., Jegede, 2008, Jegede \& Owolabi, 2005; Soh, 1998a, 1998b). Further analysis of variances (Yushau, 2006) as well as correlation and predictive affirmations (Cázares, 2010) of computer proficiencies and performances are performed.

With a growing body of literature supporting insignificant changes in pedagogical strategies relative to student learning and cognitive capabilities, this study is designed to respond to the dearth of research regarding computer attitude of teaching faculty in higher education in Ghana and to validate Selwyn's CAS (1997) in a different socio-cultural context. Its implication for technology-based pedagogy and performance are further explored. Specific research questions are: What are the computer attitudes of the teaching faculty in public universities? What are the relationships of the sub- attitude constructs to the general computer attitudes? 


\section{Methodology}

\section{Setting and Participants}

The study was conducted in three public conventional universities in Ghana. Participants consisted of systematic randomly selected multidiscipline academic teaching faculty. A questionnaire was administered to participants with the option to respond to either a print-based or electronicbased survey. Rationale for the two modalities of data collection was flexibility and choice. Participation was voluntary and confidential.

\section{Measurement}

Modeling Selwyn's (1997) CAS, the teaching staff responded to a set of 21-item statements on a 5-point Likert scale: from Strongly Agree (4) to Strongly Disagree (0). The CAS was composed of four distinct but complementary attitude constructs namely affective, perceived usefulness, behavior, and perceived behavioral control. Affective attitude consisted of 6 items depicting feelings such as fear, apprehension, discomfort, and hesitation towards computers and ICT. Perceived usefulness attitude was composed of 5 items and measured the degree to which the user found the computer relevant in improving job performance. Behavior attitude measured intentions and actions with regard to computers and consisted of 5 items, and perceived behavioral control attitude (shortened to perceived control attitude) consisted of 5 items and measured management, ease, or difficulty of computer use. The general computer attitude is the summated set of the 21 -item constructs and reflected the degree of respondents' attitudes towards computer technology and ICT, which means that statements were composed to reflect heterogeneity and measurable responses from which the computer attitude was inferred. Potential scores ranged from 0 to 84 . As a hypothetical construct, attitude can be inferred from measurable responses and is most useful when relevant responses are categorized into various subgroups or domains (Ajzen, 2005). Prior

\section{Reliability and validity}

Prior to administering the questionnaire, some items in Selwyn's (1997) CAS were modified to fit the target audience and tested for construct validity through expert reviews and field testing with six comparable audiences. A reliability test using Cronbach's coefficient $(\alpha)$ was computed for the overall computer attitude scale and all sub-scales. Negative items constructed for internal consistency were reversed for the purpose of the analysis. The Levene's Test was performed to validate assumption of variance equality.

With a return rate of nearly $63 \%$ of administered questionnaires, data were pooled for descriptive and inferential statistical analyses using SPSS 17.0. The computer attitude sub-domains were analyzed for significant mean variations using ANOVA. Further analyzes were conducted to compare the relationships and structure between each of the sub-constructs and the general computer attitude.

\section{Results}

Table 1 shows the means, standard deviation, and reliability coefficients of the sub-constructs and the overall computer attitude. At a significant construct validity $(p<0.01)$, all reliability scores are higher than .70, implying excellent internal consistencies of assessment items. The overall reliability Cronbach coefficient $(\alpha)$ for computer attitude is .868 with inter-class correlation coefficient between .837 and .896 . Behavioral attitude is highest at $\alpha=.952$ and lowest for control attitude at $\alpha=.735$. Together with others tabulated, these results compare favorably with Selwyn's (1997) internal reliability coefficient $(0.90)$ and significant construct validity $(p<0.001)$. 
Of the four constructs, the mean $(\bar{x})$ of the affective attitude was highest at approximately 22 out of 24 . Behavioral control attitude score is the least at nearly 16 out of 20.

Table 1: Means, Standard Deviation, and Reliability Coefficients

\begin{tabular}{lcccccc}
\hline Attitude Construct & $\mathrm{N}$ & $\begin{array}{c}\text { No. of } \\
\text { Items }\end{array}$ & Mean & SD & $\begin{array}{c}\text { Cronbach's } \alpha \\
\text { (Standardized } \\
\text { Items) }\end{array}$ & Sig. \\
\hline Affective & 163 & 6 & $21.80[24]$ & 3.78 & .836 & .000 \\
Usefulness & 163 & 5 & $17.10[20]$ & 3.34 & .870 & .000 \\
Behavior & 163 & 5 & $16.06[20]$ & 5.81 & .952 & .000 \\
Control & 163 & 5 & $15.87[20]$ & 2.52 & .735 & .000 \\
Computer Attitude & 163 & 21 & $70.54[84]$ & 10.92 & .868 & \\
\hline
\end{tabular}

Note: All reliability scores are significant at $p<0.001$. Potential means are in parenthesis. Grand mean on mean scores is 17.71 .

The mean of general computer attitude is 70.54 out of 84 . The range is 5.94 with a minimum 15.97 and maximum 21.80 , suggesting relatively high positive attitude towards computers and ICT. The percentile ranking shows a score of 65 at the $25^{\text {th }}$ percentile, 74 at the $50^{\text {th }}$ percentile, and 79 at the $75^{\text {th }}$ percentile. As a normative guide to interpretation, Selwyn (1997) described scores below the $25^{\text {th }}$ percentile (35) as relatively negative attitude towards computers and scores above the $75^{\text {th }}$ percentile (51) as relatively positive attitude towards computers. Based on these standards, only one participant (1.2\%) reflected a negative attitude in this present study. Compared with the other sub-constructs, the standard deviation of behavioral attitude varied most widely.

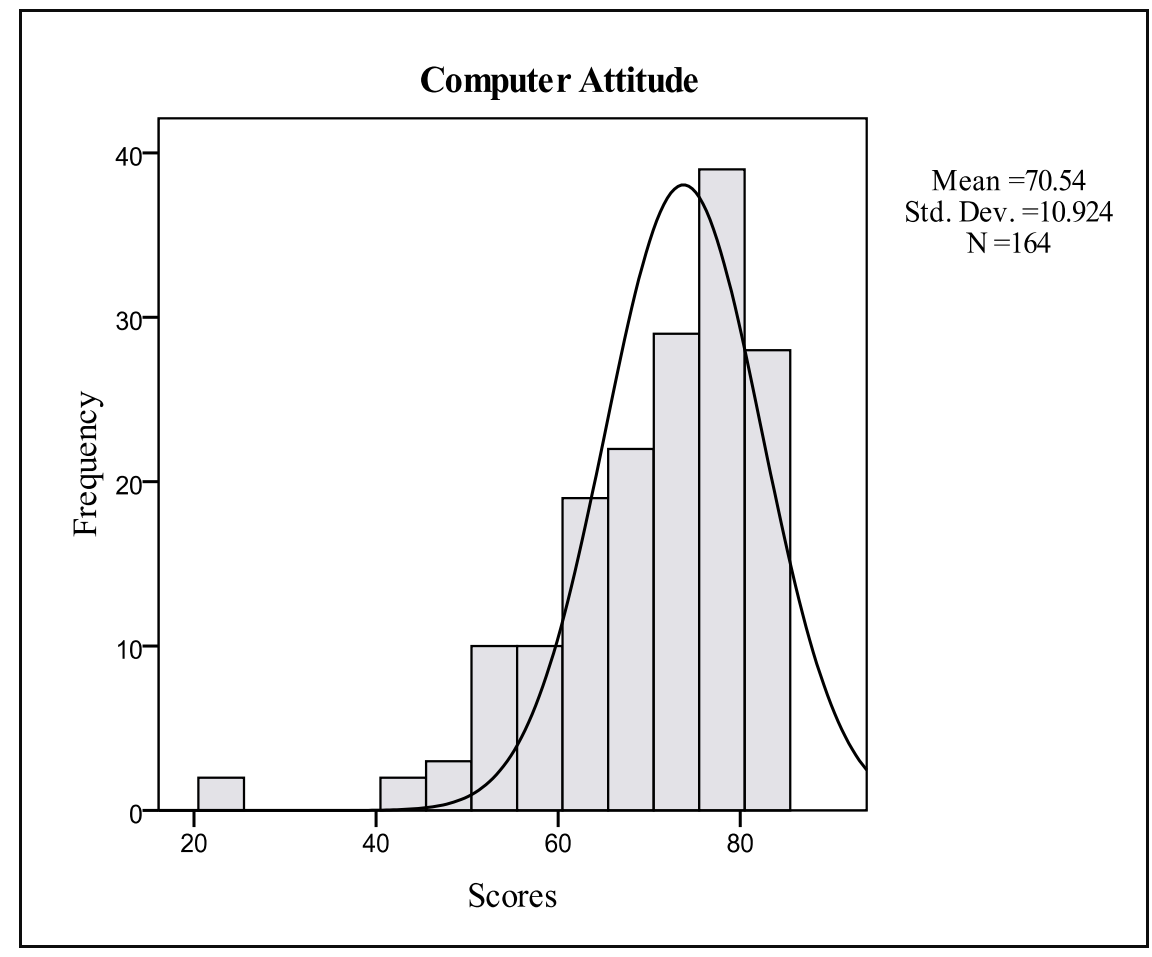

Figure 1: Teaching Faculty Computer Attitude Note: Computed from survey data. 
Figure 1 illustrates the distribution of the computer attitude. The distribution is leptokurtic (slightly positive kurtosis) and negatively skewed, depicting an extreme score at the lower end. Suggested by Keppel and Wickens (2004), real data are little more scattered, hence, the relatively few over-dispersed scores were considered as valid part of the distribution and included in the analysis.

Confirmed by the Levene's Test at $p$ value $=.05$, the equal mean differences assumption was rejected; hence, a post hoc analysis was performed to compare significant differences and magnitude .Table 2 shows the results of the one-way analysis of variance (ANOVA) applied in comparing the means of the four computer attitude constructs. All four sub-constructs differed across computer attitude and are significant at $F(3,162)=96.812, p=.000$. Likewise, the $F$ values for the four sub-constructs ANOVAs are also significant with $p$ values between .000 and .002 . For example, $F(5,162)=3.833, p=.002$ for affective attitude; $F(4,162)=19.944, p=.000$ for perceived usefulness attitude; $F(4,162)=7.172, p=.000$ for perceived control attitude and $F(4$, $162)=9.745, p=.000$ for behavioral attitude (see Table 3 ).

Table 2: ANOVA of Computer Attitude

\begin{tabular}{rrrrrrr}
\hline \multicolumn{1}{c}{ Source } & & SS & $d f$ & MS & Sig \\
\hline \multirow{2}{*}{ Computer Attitude } & Between Groups & 4294.633 & 162 & 26.51 & & \\
& Within Groups & 3789.270 & 3 & 1263.09 & 96.812 & \\
& Total & 8083.903 & 165 & & \\
& & & & \\
& &
\end{tabular}

Note: $p<.05$

Table 3: ANOVA of Computer Attitude Sub-Constructs

\begin{tabular}{lrrrrrr}
\hline \multicolumn{1}{c}{ Source } & SS & $d f$ & MS & $F$ & Sig. \\
\hline Affective Attitude & Between Groups & 386.286 & 162 & 2.384 & \multirow{2}{*}{ (16.833 } & .002 \\
& Within Groups & 7.505 & 5 & 1.501 & & \\
Terceived Usefulness Attitude & 393.791 & 167 & & & \\
& Between Groups & 374.245 & 162 & 2.310 & & \\
& Within Groups & 24.817 & 4 & 6.204 & 19.944 & .000 \\
Perceived Control Attitude & Total & 399.062 & 166 & & & \\
& Between Groups & 187.806 & 162 & 1.159 & & \\
& Within Groups & 8.852 & 4 & 2,213 & 7.172 & .000 \\
Behavioral Attitude & Total & 196.658 & 166 & & & \\
& Between Groups & 1091.602 & 162 & 6.738 & & \\
& Within Groups & 12.324 & 4 & 3.081 & & .000 \\
& Total & 1103.926 & 166 & & & \\
\hline
\end{tabular}

Note: $p<.05$. 
Significant variations among the levels of computer attitude of the teaching faculty suggest combined and differential relationships on computer attitude. The relationships between each of the sub-construct attitudes and computer attitude are illustrated using plots of group means in Figures $2-5$. Each of the plots shows a unique relationship between the construct and computer attitude. For example, with the exception of sharp increases in the mean scores at the lower ends of both perceived affective and usefulness curves, the relationships with computer attitude are highly positive. In contrast, the levels of fluctuations are high for responses to behavioral and control attitudes suggesting initial unstable relationships. There is positive and stable relationship to computer attitude as the mean scores increases for both constructs. Suggestively, inadequate control and discomfort could negatively impact computer technology use.

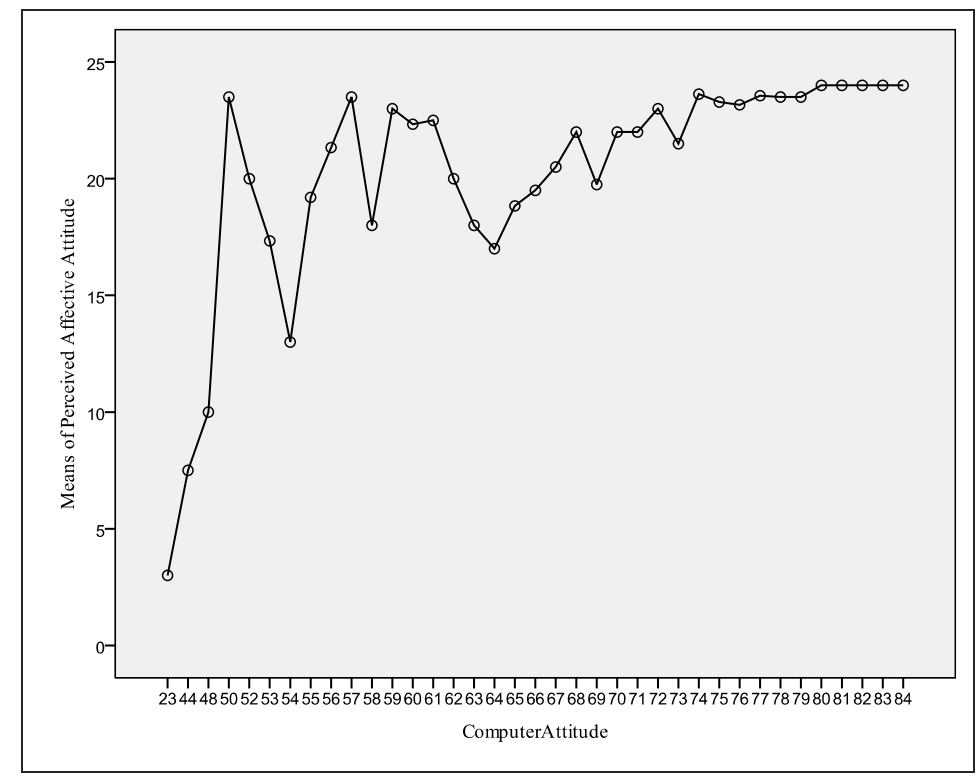

Figure 2: Structure and Relationship between Affective Attitude and Computer Attitude

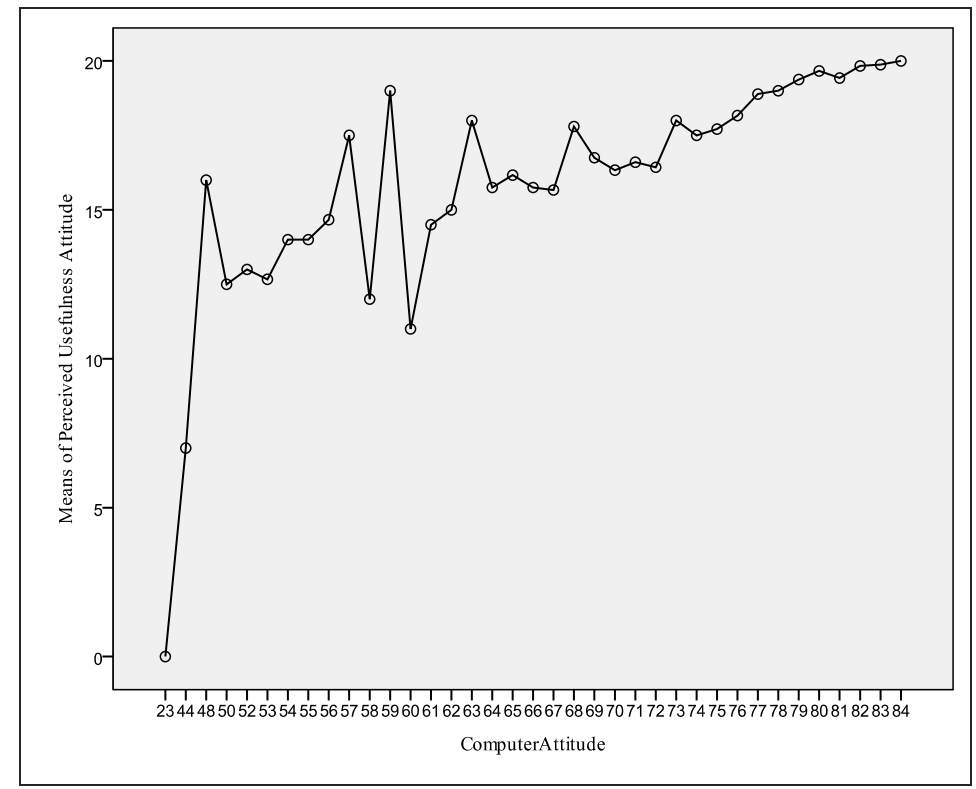

Figure 3: Structure and Relationship between Perceived Usefulness Attitude and Computer Attitude 


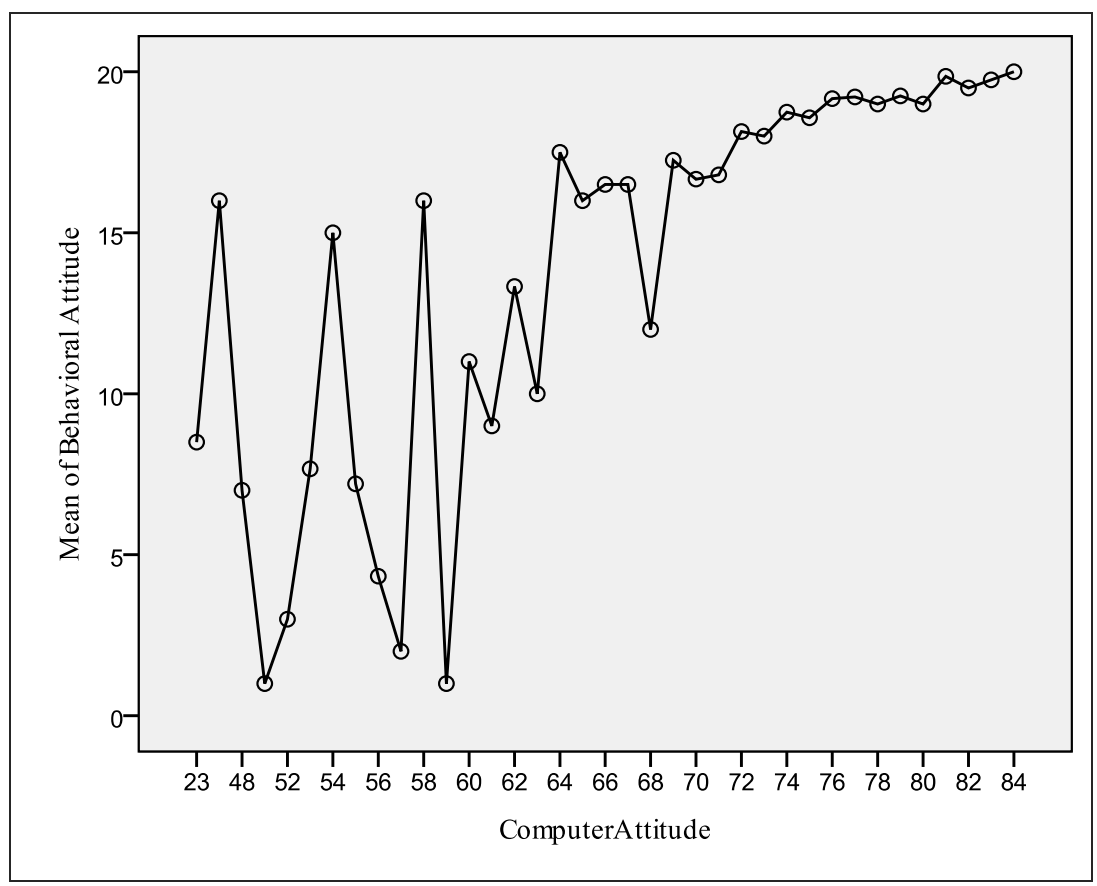

Figure 4: Structure and Relationship between Behavioral Attitude and Computer Attitude

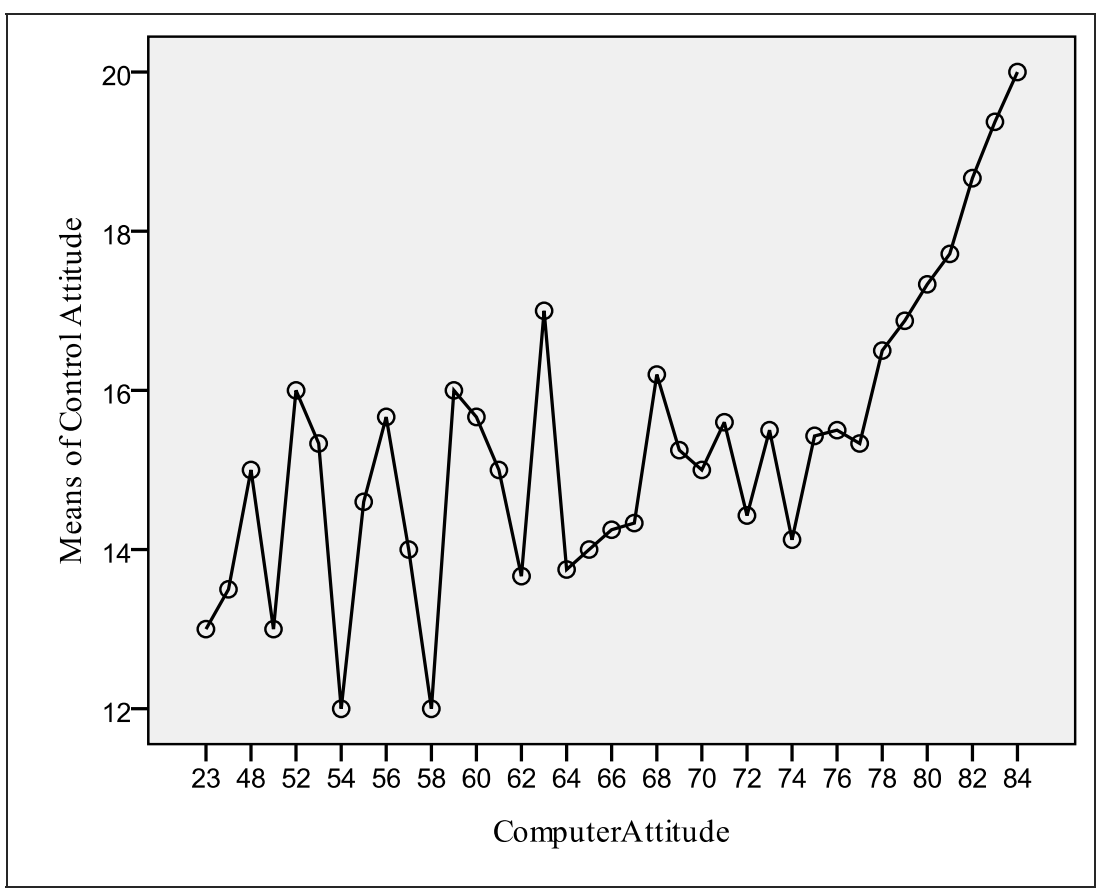

Figure 5: Structure and Relationship between Perceived Control Attitude and Computer Attitude 


\section{Discussion}

The results indicate teaching staff in these universities have relatively high and positive attitudes toward computer technology and ICT. The computer attitude was directly associated with affective, perceived usefulness, perceived behavioral control, and behavioral attitudes, and their means differed significantly on the different levels of computer attitude. For example, with a mean score of $22(91 \%)$, affective computer attitude is rated the highest of the four constructs, suggesting high affinity towards the use of ICT by the majority of the teaching staff. Adequate knowledge and minimal technophobia (fear of advanced technology, Online Merriam-Webster Dictionary, 2011) can allay fears for technology use. Yaghi and Abu-Saba (1998) reported that computer anxiety of teachers was reduced when they used computers for educational tasks. Stricker and Widiger (2003) asserted fear and anxiety could dominate one's cognitive process to the point of interfering with daily functioning.

Perceived usefulness computer attitude measured the degree to which the user finds the attitude object relevant in improving job performance. The mean is the second highest at $17.10(86 \%)$ underlying computer attitude and seems to describe high positive relationships. The result compares favorably with Yushau's (2006) average score at 79\%. Yushau described the score as more positive attitude in a study of teachers' attitude towards pedagogical usefulness of computer. Karahanna, Straub, and Chervany (1999) found perceived usefulness as the only belief underlying attitude, on both adopting and continuing use of Windows technology innovation. Perceiving an innovation as useful can influence its potential adoption (Rogers, 2003)

Behavioral attitude measured regular use and possible avoidance of computers. The mean $(\overline{\mathrm{x}})$ is 16.06 or $80 \%$ with relatively high standard deviation, which suggests a wider margin between respondents' level of computer experience and usage (see Figure 4). The results could also be interpreted as positive intentions and continued actions toward computer-technology as respondents develop purposeful ICT competencies. Ajzen (2005) asserted a behavior belief is the subjective probability that the behavior can produce a given behavior. A change in behavior can occur when old practices or what used to serve the individual best are no longer productive and compatible with new practices.

Of the four constructs, perceived control attitude is the lowest ( $\overline{\mathrm{x}}=15.9$ or $79 \%)$, but it is not interpreted as lack of control. The relatively lowest score could be explained by extreme scores resulting from inconsistencies in some of the responses to statements intended for construct validity. However, the result is consistent with that of Chin (n.d.) who reported relatively low positive control attitude. In a related study, Jegede et al. (2007) found perceived control and affective attitudes dominating in predicting ICT competence. Recall, behavioral control was determined by the total set of accessibility and control beliefs, and the strength of each control belief was aggregated to reflect the actual behavioral control (Ajzen, 2005).

In general, the results of the present study compare with the sequential relationships of the subconstructs and computer attitude as reported by Chin (n.d.). Chin reported a general positive attitude mean score of 7.04 on a scale of 10 for Singapore University teachers. Differentiating the scores into attitudinal domains, the affective component was highest (8.05), followed by usefulness (7.52), behavior (6.96), and control (6.47). Jegede and Owalabi (2005) reported an overall computer attitude of South Western Nigerian higher education teachers at 7.90, and the mean was highest for perceived control attitude, followed by behavior, usefulness, and affective attitudes.

It is worth noting that with fairly positive computer attitude, mathematics professors in King Fahd University of Petroleum \& Minerals found it difficult to translate that energy into practice (Yushau, 2006). Computer experience did not affect computer attitude and their pedagogical usefulness. 


\section{Implications for Technology-based Performance}

Driven by increasing demand for educational technology and pedagogical innovation, many colleges and universities are supplementing conventional practices with digitized instructional and teaching strategies. Attitude towards ICT or computers was designed in this study with performance descriptive factors such as productive, usefulness, management, control, and problem solving. Computer attitude of the teaching faculty was predicted by the interaction of the four attitu-

dinal constructs, which can potentially influence the development of the theory of personal attributes such as mastery of necessary skills and future behaviors toward computer integration in higher education. For instance, personalizing goals, preferences, and biases is influenced by affective attitude. Affect can be regulated to motivate adaptive behaviors, while motivation is a function of rational decision making, learning, and creativity. Exercising behavioral control and connecting emotionally to the computer has the potential to increase innovation-decision making and the speed with which an innovation such as technology can be adopted and utilized.

With increasing access to global education and instructional resources via the Internet, getting familiar with technology and its operations can influence filtering of information for quality and the selection of appropriate pedagogical toolkits or resources for the development of higher-order cognitive skills of students. In a developing country such as Ghana, where computer to student ratio is low, the overall positive computer attitude of the teaching faculty can potentially influence demands and a greater call to increase investment for equity and access to computers and educational technology in the universities. There is a greater and inherent risk to investing in computers by the Ministry of Education when end-users like the teaching faculty are unable and/or unwilling to reciprocate in their utilization in the classroom and for other professional practices. Recall that mathematics professors in King Fahd University of Petroleum \& Minerals could not translate the reported fairly positive computer attitude into practice (Yushau, 2006).

Nonetheless, both theoretical and practical understanding of the dynamics of human-computerinteraction, as well as subjective human-behaviors such as attitude and self-efficacy, can provide the means to design interventions and supportive learning and teaching environments. Results of computer attitude studies can provide the basis for diagnosis and management of identified subjective human factors, such as self-efficacy, self-confidence, fear, anxiety, and control to influence technology-based performance. Saadé and Kira (2009) have reported increasing levels of self-efficacy as a strong significant mediating influence in reducing anxiety towards learning management systems (LMS). The composite set of computer attitude can serve as precursor to computer-technology proficiencies or ICT adoption, usage, and performance when contextual factors are well-defined and established in the universities.

\section{Conclusion}

A teaching faculty's positive attitude towards computers can direct productive use and management of ICT/computer-technologies. This study validated Selwyn's (1997) CAS and provided evidence to support the relationship of affective, perceived usefulness, behavioral and perceived control attitude factors to computer attitude. With the right attitude and needed institutional support, teaching faculty acting as important catalysts of change can respond to the nuances of information and communication technology (ICT) for the needed transformation.

\section{Limitations and Future Research}

We propose studies in private and public universities worldwide for academic and practical significance since the present study was limited to public universities in Ghana. Further study on relational and invariance of CAS across demographic factors such as gender, age, academic status, and subject discipline is proposed for their differential influence. Attitude affects the way 
people interact with and utilize their environment and should be studied, particularly for its effect on computer-technology adoption, competency, utilization, and performance.

\section{References}

Ajzen, I. (1988). Attitude, personality, and behavior. Chicago, IL: Dorsey Press.

Ajzen, I. (2005). Attitudes, personality, and behavior (2nd ed.). Milton-Keynes, UK: Open University Press/McGraw-Hill.

Albion, P. R. (1999). Self-efficacy beliefs as an indicator of teachers' preparedness for teaching with technology. In J. D. Price, J. Willis, D. A. Willis, M. Jost, \& S. Boger-Mehall (Eds.), Proceedings of the Society for Information Technology \& Teacher Education International Conference, (pp. 1602-1608). Chesapeake, VA: AACE.

Bonk, C. J., \& Dennen, V. (2003). Frameworks for research, design, benchmark, training, and pedagogy in Web-based distance education. In M. G. More \& B. Anderson (Eds.), Handbook of distance education (pp. 331-348). Mahwah, N.J: Lawrence Erlbaum Associates.

Cázares, A. (2010). Proficiency and attitudes toward information technology use in psychology undergraduates. Computers in Human Behavior, 26, 1004-1008. doi:10.1016/jchb2010.02.015

Chin, T. O. (n.d.). Assessment of staff attitudes towards computers and its implications on the use of IT in school. Anglo-Chinese School (Independent). Singapore. Retrieved from http://www3.moe.edu.sg/edumall/mpite/edtech/papers/b6_3.pdf

Hsu, M. K., Wang, W. S., \& Chiu, K. K. (2009). Computer attitude, anxiety and self-efficacy on statistical software adoption behavior: An empirical study of online MBA learners, Computers in Human Behavior, 25, 412-420.

Jegede, P. O. (2007, September). Computer attitude as correlates of computer self efficacy among South Western Nigerian higher education teachers. Paper presented at Sixth International Internet Education Conference, Cairo: Egypt.

Jegede, P. O. (2008). ICT attitudinal characteristics and use level of Nigeria teachers. Issues in Informing Science and Information Technology, 5, 261-265.

Jegede, P. O., Dibu-Ojerinde, O. O., \& llori, M. O. (2007). Relationship between ICT competence and attitude among some Nigerian tertiary institution lecturers. Educational Research and Review, 2(7), 172175.

Jegede, P. O., \& Owolabi, O. (2005). Effects of professional status, subject discipline and computer access on computer attitudes among teacher educators in Nigeria Colleges of Education. Information Technology Journal, 4(2), 58-162.

Karahanna, E., Straub, D. W., \& Chervany, N. L. (1999). Information technology adoption across time: A cross-sectional comparison of pre-adoption and post-adoption beliefs. Management Information System Quarterly, 23(2), 183-213.

Keppel, G., \& Wickens, T. D. (2004). Design and analysis: A researcher's handbook (4th ed.). Upper Saddle River, NJ: Pearson Prentice Hall.

Kim, H., \& Davis, K. (2008). Toward a comprehensive theory of problematic Internet use: Evaluating the role of self-esteem, anxiety, flow, and the self-rated importance of Internet activities. Computers in Human Behavior, 25, 490-500. doi:101.1016/j.chb.2008.11.001

Larbi-Apau, J. A. (2011). Computer attitude, and the impact of personal characteristics and information and communication technology adoption patterns on performance of teaching faculty in higher education. (Doctoral Dissertation). Ann Arbor, MI: ProQuest UMI.

Morris, L. V., Xu, H., \& Finnegan, C. L. (2005). Roles of faculty in teaching asynchronous undergraduate courses. Journal of Asynchronous Learning Networks (JALN), 9(1), 65-82. 
Online Merriam-Webster Dictionary (2011). Technophobia. Retrieved from http://www.merriamwebster.com/dictionary/technophobia

Park, Y., \& Moser, F. Z. (2008). Identifying the role of international consortium "MIT/LINC" in supporting the integration of ICT in higher education in emerging countries. Journal of Science Education and Technology, 17(20), 197-207. doi: 10.1007/s10956-007-9056-4)

Rogers, E. M. (2003). Diffusion of innovations (5th ed.). New York, NY: Free Press.

Saadé, R. G., \& Kira, D. (2009). Computer anxiety in elearning: The effect of computer self-efficacy. Journal of Information Technology Education, 8, 177-191. Retrieved from http://www.jite.org/documents/Vol8/JITEv8p177-191Saade724.pdf

Schwarzer, R., \& Jerusalem, M. (1995). Generalized self-efficacy scale. In J. Weinman, S. Wright, \& M. Johnston (Eds.), Measures in health psychology: A user's portfolio, causal and control beliefs (pp. 3537). Windsor, UK: NFER-NELSON.

Selwyn, N. (1997). Students' attitude toward computers: Validation of a computer attitude scale for 16-19 education. Computer Education, 28(1), 35-41.

Stricker, G., \& Widiger, T. A. (Eds.). (2003). Handbook of psychology: Clinical psychology. Hoboken, N.J: John Wiley \& Sons.

Soh, K. C. (1998a). Cross cultural validity of Selwyn Computer Attitude Scale. Unpublished manuscript.

Soh, K. C. (1998b). Teacher use of computer checklist: A validation study. Unpublished manuscript.

Yaghi, H. M., \& Abu-Saba, M. B. (1998). Teachers' computer anxiety: An international perspective. Computers in Human Behavior, 14(2), 321-336.

Yushau, B. (2006). Computer attitude, use, experience, software familiarity, and perceived pedagogical usefulness: The case of mathematics professors, Eurasia. Journal of Mathematics, Science and Technology Education, 2(3), 1-17.

\section{Biographies}

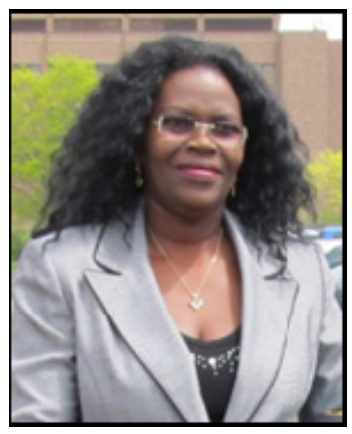

Josephine A. Larbi-Apau, Ph.D. is adjunct assistant professor in Instructional Technology at the Graduate School, Keiser University, Florida and a consultant in instruction and performance technologies, curriculum development and training management, ICT and higher education policy and research, and integrated learning management systems. Josephine has previously worked in various capacities as assistant director of education, coordinator of integrated science, trainer of trainers, head of department, and a high school teacher with the Ghana Education Service. She is a recipient of many honors and scholarships including Dissertation Fellowship, 2011 and the prestigious Wayne State University Graduate School/College of Education Thomas C. Rumble Fellowship, 2008-2010, Winrcock International Fellowship, Cornell University, 2002-3, and Outstanding Scholastic Achievement and Excellence, GKIHS, Wayne State University, 2008. Josephine has co-authored both refereed and non-refereed scholarly papers on performance-based measurement, communication in performance training, program evaluation, education and productivity, and microbiology. Her current research is focused on computer technology and ICT-based performance in higher education. She can be contacted at jlarbiapau@wayne.edu. 


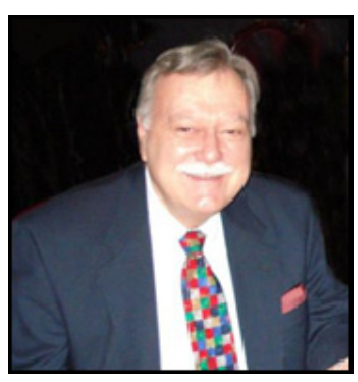

James L. Moseley, Ed.D, LP C, CHES, CPT, is associate professor at Wayne State University's College of Education Instructional Technology Program. He is a licensed professional counselor in the state of Michigan, a certified health education specialist, and a certified performance technologist. He teaches and advises doctoral students in program evaluation, performance improvement and consulting, curriculum development, and adult learning. He is the recipient of many honors and awards including the 2012 Outstanding Graduate Mentor Award in the Social Sciences, Business, and Education and the 2012 Kathleen Reilly Koory Endowed Faculty Development Award from Wayne State University. Moseley was co-editor with Joan C. Dessinger of the ISPI/Wiley Handbook of Improving Performance in the Workplace: Volume 3: Measurement and Evaluation. He is co-author with Darlene M. Van Tiem and Joan C. Dessinger of award-winning companion books, Fundamentals of Performance Technology: A Guide to Improving People, Process, and Performance 1st and 2nd editions) and Performance Improvement Interventions: Enhancing People, Processes, and Organizations through Performance Technology. He recently co-authored with Van Tiem and Dessinger Fundamentals of Performance Improvement: Optimizing Results through People, Process, and Organizations, 3rd edition. Moseley has also co-authored with Dessinger Confirmative Evaluation: Practical Strategies for Valuing Continuous Improvement and Training Older Workers. He holds six graduate degrees including M.A., M.S.L.S., M.Ed., M.S.A., Ed.S, and Ed.D. He holds certificates in high school teaching, health administration, and gerontology. Moseley is a member of ISPI and ASTD and is frequently invited to present at local, regional, national, and international conferences. He is currently co-editor in chief of the Performance Improvement Journal. He can be contacted at james.moseley@,wayne.edu. 